\title{
Polymorphic hydroxylation of perhexiline maleate in man
}

\author{
R G COOPER, D A P EVANS*, AND E J WHIBLEY \\ From the Nuffield Unit of Medical Genetics, Department of Medicine, University of Liverpool, \\ Liverpool L69 $3 B X$.
}

SUMMARY Long term perhexiline maleate therapy causes peripheral neuropathy and hepatic damage in certain subjects. An association between these adverse reactions and a genetically determined relative inability to hydroxylate debrisoquine has been described. This association could indicate either that the effects of perhexiline impair debrisoquine oxidation thus producing a phenocopy, or that perhexiline is polymorphically hydroxylated and that the polymorphism is controlled by the same alleles as control the debrisoquine polymorphism. To test the second possibility, a study investigating the hydroxylation status of a population of healthy volunteer subjects has teen performed using perhexiline maleate.

Hydroxylation phenotyping was performed on 50 normal volunteers. A standard oral dose was given and plasma and urinary perhexiline, 4-monohydroxyperhexiline (MI metabolite), and 4 'monohydroxyperhexiline (MIII metabolite) was measured. The 24-hour plasma perhexiline concentration, the 24-hour plasma MI metabolite concentration, and 12 to 24-hour urinary MI metabolite excretion were clearly bimodal, suggesting the existence of a polymorphism for ferhexiline hydroxylation. Poor metabolisers represent $6 \%$ of the population studied. Known poor metabolisers of debrisoquine are also poor metabolisers of perhexiline, while known extensive metabolisers of debrisoquine are also extensive metabolisers of perhexiline, indicating that in white British subjects the hydroxylation polymorphism is under identical genetic control for both compounds. The poor metaboliser sub-group exhibited the highest plasma perhexiline levels.

Perhexiline phenotyping separates the poor and extensive metaboliser phenotypes much more clearly than other tests and defines a sub-group at risk from perhexiline toxicity. Pretreatment phenotyping using this test, followed by exclusion of poor metabolisers from perhexiline therapy, should substantially reduce the incidence of major adverse effects.

Perhexiline maleate is an effective anti-anginal agent. ${ }^{12}$ It has achieved notoriety because of a number of serious side effects including peripheral neuropathy, ${ }^{34}$ hepatic damage, ${ }^{56}$ weight loss, ${ }^{7}$ hypoglycaemia, ${ }^{8}$ proximal myopathy, ${ }^{9}$ and papilloedema $^{10}$ which are all reversible with cessation of therapy except when cirrhosis complicates hepatic damage. ${ }^{1112}$ Only certain subjects appear to suffer these side effects and a genetic susceptibility has been proposed to explain this. ${ }^{13}$

Large inter-individual variations of the plasma half life of perhexiline are thought to be the result of differences in the rate of metabolism of the drug. ${ }^{14}$

*Present address: Department of Medicine, Riyadh Armed Forces Hospital. PO Box 7897, Riyadh 11472. Saudi Arabia.

Received for publication 11 June 1983

Accepted for publication 20 July 1983.
Patients developing peripheral neuropathy exhibit greater plasma perhexiline levels with prolonged plasma half lives when compared with non-neuropathic patients on equivalent oral dosage. ${ }^{15}$ Neuropathic persons appear, therefore, to have impaired drug metabolism or reduced elimination or both.

The highly lipophilic nature of perhexiline necessitates the hepatic manufacture of water soluble monohydroxy and dihydroxy metabolites if renal elimination is to take place. Impaired oxidation capacity would, therefore, reduce renal excretion with accumulation of the parent compound causing toxic side effects. Debrisoquine oxidation phenotyping studies have demonstrated a bimodal distribution of results. ${ }^{1617}$ Most subjects are of the extensive oxidation phenotype while approximately 
TABLE 1 Results of perhexiline studies in 50 random white British subjects of unknown phenotype. Also shown are the results in known extensive and poor metabolisers of debrisoquine and sparteine.

\begin{tabular}{|c|c|c|c|c|c|c|c|c|c|c|}
\hline \multirow{2}{*}{$\begin{array}{l}\text { Test } \\
\text { No }\end{array}$} & \multirow[t]{2}{*}{ Age } & \multirow[t]{2}{*}{ Sex } & \multirow{2}{*}{$\begin{array}{l}\text { Weight } \\
(k g)\end{array}$} & \multirow[t]{2}{*}{ Smoking } & \multicolumn{2}{|c|}{ Plasma results } & \multicolumn{4}{|l|}{ Urine results } \\
\hline & & & & & $\begin{array}{l}\text { Perhexiline } \\
(\mu \mathrm{g} / \mathrm{ml})\end{array}$ & $\begin{array}{l}\text { MI metabolite } \\
(\mu \mathrm{g} / \mathrm{ml})\end{array}$ & $\begin{array}{l}\text { MI metabolite } \\
\text { excretion }(\mu g)\end{array}$ & $\begin{array}{l}\text { As \% of } \\
\text { total dose }\end{array}$ & $\begin{array}{l}\text { MIII metabolite } \\
\text { excretion }(\mu g)\end{array}$ & $\begin{array}{l}\text { As \% of } \\
\text { total dose }\end{array}$ \\
\hline 1 & 22 & $\mathbf{F}$ & $58 \cdot 5$ & 0 & 0.05 & 0.43 & 4500 & 1.5 & 750 & 0.3 \\
\hline 2 & 20 & F & $59 \cdot 0$ & 0 & 0.05 & 0.50 & 6545 & $2 \cdot 2$ & 1020 & 0.3 \\
\hline 3 & 22 & $\mathbf{M}$ & $65 \cdot 8$ & 0 & 0.05 & 0.39 & 9938 & $3 \cdot 3$ & 2063 & 0.7 \\
\hline 4 & 20 & $\mathbf{F}$ & 63.5 & $25 \mathrm{C}$ & 0.5 & 0.02 & 54 & 0.02 & 455 & 0.2 \\
\hline 5 & 20 & $\mathbf{M}$ & 69.9 & 0 & 0.1 & 0.38 & 6752 & $2 \cdot 3$ & 5019 & 1.7 \\
\hline 6 & 29 & $\mathbf{M}$ & $75 \cdot 3$ & 0 & 0.05 & 0.34 & 4160 & 1.4 & 1120 & 0.4 \\
\hline 7 & 22 & $\mathbf{M}$ & $67 \cdot 1$ & 0 & 0.04 & 0.52 & 2670 & 0.9 & 630 & 0.2 \\
\hline 8 & 20 & $\mathbf{M}$ & $60 \cdot 3$ & 0 & 0.04 & 0.51 & 4895 & 1.6 & 1320 & 0.4 \\
\hline 9 & 20 & $\mathbf{M}$ & $70 \cdot 0$ & 0 & 0.05 & 0.51 & 4030 & $1 \cdot 3$ & 1105 & 0.4 \\
\hline 10 & 19 & M & $76 \cdot 2$ & 0 & 0.07 & 0.31 & 3240 & $1 \cdot 1$ & 540 & 0.2 \\
\hline 11 & 19 & $\mathbf{M}$ & 69.9 & 0 & 0.05 & 0.48 & 7800 & 2.6 & 1600 & 0.5 \\
\hline 12 & 23 & $\mathbf{M}$ & $76 \cdot 2$ & 0 & 0.05 & 0.57 & 7975 & 2.7 & 1980 & 0.7 \\
\hline 13 & 28 & $\mathbf{M}$ & $82 \cdot 6$ & $30 \mathrm{C}$ & 0.21 & 0.27 & 2250 & 0.8 & 2050 & 0.7 \\
\hline 14 & 25 & $\mathbf{F}$ & 54.0 & 0 & 0.09 & 0.35 & 2820 & 1.0 & 810 & 0.3 \\
\hline 15 & 25 & $\mathbf{F}$ & $60 \cdot 8$ & 0 & 0.12 & 0.55 & 6460 & $2 \cdot 2$ & 855 & 0.3 \\
\hline 16 & 30 & $\mathbf{F}$ & $60 \cdot 3$ & 0 & 0.11 & 0.58 & 5880 & $2 \cdot 0$ & 1920 & 0.6 \\
\hline 17 & 22 & $\mathbf{M}$ & $77 \cdot 1$ & 0 & 0.08 & 0.34 & 5355 & 1.8 & 2205 & 0.7 \\
\hline 18 & 43 & $\mathbf{M}$ & $76 \cdot 2$ & 0 & 0.07 & 0.61 & 4313 & 1.4 & 1050 & 0.4 \\
\hline 19 & 30 & $\mathbf{F}$ & $66 \cdot 7$ & 0 & 0.09 & 0.46 & 2145 & 0.7 & 619 & 0.2 \\
\hline 20 & 21 & $\mathbf{F}$ & 54.4 & 0 & 0.09 & 0.72 & 3630 & $1 \cdot 2$ & 1100 & 0.4 \\
\hline 21 & 20 & F & $58 \cdot 1$ & 0 & 0.09 & 0.58 & 3200 & $1 \cdot 1$ & 1360 & 0.5 \\
\hline 22 & 20 & $\mathbf{M}$ & 64.9 & 0 & 0.09 & 0.36 & 5720 & 1.9 & 1625 & 0.5 \\
\hline 23 & 45 & $\mathbf{F}$ & $50 \cdot 0$ & 0 & 0.1 & 0.51 & 2003 & 0.7 & 630 & 0.2 \\
\hline 24 & 19 & $\mathbf{M}$ & 68.0 & 0 & 0.07 & 0.35 & 3870 & $1 \cdot 3$ & 428 & 0.1 \\
\hline 25 & 19 & $\mathbf{M}$ & $71 \cdot 2$ & 0 & 0.14 & 0.43 & 2700 & 0.9 & 3100 & 1.0 \\
\hline 26 & 19 & $\mathbf{M}$ & 64.9 & 0 & 0.37 & 0.02 & 70 & 0.02 & 998 & 0.3 \\
\hline 27 & 18 & $\mathbf{M}$ & 63.5 & 0 & $0 \cdot 15$ & 0.80 & 3328 & $1 \cdot 1$ & 3410 & $1 \cdot 1$ \\
\hline 28 & 18 & $\mathbf{M}$ & 58.0 & 0 & $0 \cdot 1$ & 0.68 & 3320 & $1 \cdot 1$ & 4200 & 1.4 \\
\hline 29 & 19 & $\mathbf{M}$ & $63 \cdot 5$ & 0 & 0.16 & 0.82 & 4200 & 1.4 & 2325 & 0.8 \\
\hline 30 & 45 & $\mathbf{F}$ & $55 \cdot 3$ & $10 \mathrm{C}$ & 0.04 & 0.52 & 3990 & $1 \cdot 3$ & 896 & 0.3 \\
\hline 31 & 22 & $\mathbf{F}$ & $52 \cdot 6$ & 0 & 0.03 & $1 \cdot 11$ & 3180 & $1 \cdot 1$ & 435 & 0.2 \\
\hline 32 & 21 & $\mathbf{F}$ & 54.0 & 0 & 0.03 & 0.78 & 3153 & $1 \cdot 1$ & 488 & 0.2 \\
\hline 33 & 22 & $\mathbf{M}$ & $50 \cdot 8$ & $5 C$ & 0.03 & 0.81 & 6780 & $2 \cdot 3$ & 1380 & 0.5 \\
\hline 34 & 20 & $\mathbf{M}$ & 74.4 & 0 & 0.03 & 0.75 & 5800 & 1.9 & 1050 & 0.4 \\
\hline 35 & 45 & $\mathbf{M}$ & 79.4 & 0 & 0.05 & 0.86 & 2430 & 0.8 & 1283 & 0.4 \\
\hline 36 & 19 & $\mathbf{F}$ & $70 \cdot 8$ & 0 & 0.03 & 0.53 & 2145 & 0.7 & 413 & $0 \cdot 1$ \\
\hline 37 & 28 & $\mathbf{M}$ & $71 \cdot 2$ & 0 & 0.07 & 0.69 & 3105 & 1.0 & 1125 & 0.4 \\
\hline 38 & 22 & $\mathbf{F}$ & $51 \cdot 0$ & 0 & 0.14 & 0.68 & 3120 & 1.0 & 2145 & 0.7 \\
\hline 39 & 27 & $\mathbf{M}$ & $92 \cdot 1$ & $5 C$ & 0.03 & 0.51 & 2700 & 0.9 & 338 & 0.1 \\
\hline 40 & 27 & $\mathbf{F}$ & $53 \cdot 5$ & $5 \mathrm{C}$ & $0 \cdot 1$ & 0.63 & 3220 & $1 \cdot 1$ & 3080 & 1.0 \\
\hline 41 & 23 & $\mathbf{F}$ & 54.0 & 0 & 0.07 & 0.55 & 3055 & 1.0 & 1040 & 0.4 \\
\hline 42 & 25 & $\mathbf{M}$ & 88.9 & $5 \mathrm{C}$ & 0.07 & 0.61 & 4520 & 1.5 & 1340 & 0.5 \\
\hline 43 & 50 & $\mathbf{F}$ & 54.0 & 0 & 0.08 & 0.71 & 1520 & 0.5 & 950 & 0.3 \\
\hline 44 & 19 & $\mathbf{F}$ & $60 \cdot 3$ & 0 & 0.04 & 0.50 & 2400 & 0.8 & 780 & 0.3 \\
\hline 45 & 23 & $\mathbf{M}$ & $76 \cdot 2$ & 0 & 0.03 & 0.60 & 5005 & 1.7 & 630 & $n \cdot 2$ \\
\hline 46 & 22 & $\mathbf{M}$ & $82 \cdot 6$ & 0 & 0.05 & 0.44 & 3990 & $1 \cdot 3$ & 950 & 0.3 \\
\hline 47 & 20 & $\mathbf{F}$ & $57 \cdot 2$ & $20 \mathrm{C}$ & 0.05 & 0.79 & 4100 & 1.4 & 1800 & 0.6 \\
\hline 48 & 22 & $\mathbf{M}$ & 74.4 & $10 \mathrm{C}$ & 0.43 & 0.03 & 14 & 0.01 & 560 & 0.2 \\
\hline 49 & 20 & $\mathbf{M}$ & 79.4 & 0 & 0.05 & $0 \cdot 76$ & 5915 & $2 \cdot 0$ & 1040 & 0.4 \\
\hline 50 & 21 & $\mathbf{F}$ & $66 \cdot 7$ & 0 & 0.03 & 0.34 & 3825 & $1 \cdot 3$ & 495 & 0.2 \\
\hline \multirow{5}{*}{$\begin{array}{l}\text { Three } \\
\text { JC } \\
\text { MH } \\
\text { JR }\end{array}$} & tensive & oxidi & ers of det & soquine an & d sparteine & & & & & \\
\hline & 44 & $\mathbf{M}$ & $80 \cdot 7$ & $10 \mathrm{C}$ & 0.03 & $0 \cdot 39$ & 2640 & 0.88 & 420 & $0 \cdot 1$ \\
\hline & 38 & $\mathbf{F}$ & $57 \cdot 2$ & $10 \mathrm{C}$ & 0.05 & 0.72 & 3612 & $1 \cdot 2$ & 1464 & 0.5 \\
\hline & 36 & $\mathbf{M}$ & $77 \cdot 6$ & 0 & 0.08 & 0.66 & 5436 & $1 \cdot 8$ & 1248 & 0.4 \\
\hline & & & & Mean & $\begin{array}{l}0.05 \\
0.03\end{array}$ & $\begin{array}{l}0.59 \\
0.18\end{array}$ & $\begin{array}{l}3895 \\
1419\end{array}$ & $\begin{array}{l}1.29 \\
0.47\end{array}$ & $\begin{array}{r}1044 \\
551\end{array}$ & $\begin{array}{l}0.33 \\
0.21\end{array}$ \\
\hline \multirow{2}{*}{\multicolumn{11}{|c|}{ Three impaired oxidisers of debrisoquine and sparteine }} \\
\hline JN & 54 & $\mathbf{M}$ & $71 \cdot 2$ & 0 & & 0.01 & 48 & 0.01 & 516 & \\
\hline IF & 21 & $\mathbf{M}$ & 79.4 & 0 & 0.33 & 0.03 & 24 & 0.01 & 240 & 0.1 \\
\hline \multirow[t]{2}{*}{ IM } & 48 & $\mathbf{M}$ & 69.9 & Pipe & 0.38 & 0.03 & 43 & 0.01 & 240 & 0.1 \\
\hline & & & & $\begin{array}{l}\text { Mean } \\
\pm \text { SD }\end{array}$ & $\begin{array}{l}0.34 \\
0.03\end{array}$ & $\begin{array}{l}0.02 \\
0.01\end{array}$ & $\begin{array}{l}38 \\
12 \cdot 7\end{array}$ & 0.01 & $\begin{array}{l}332 \\
159\end{array}$ & $\begin{array}{l}0.12 \\
0.04\end{array}$ \\
\hline
\end{tabular}

$\mathrm{C}=-$ Cigarettes $/$ day 
$9 \%$ are of poor oxidation phenotype. Their gross inability to produce 4-hydroxydebrisoquine leads to debrisoquine accumulation sometimes associated with hypotensive side effects. ${ }^{18}$ This oxidation/ hydroxylation polymorphism is under genetic control $^{17}$ and is seen in several other drugs. ${ }^{19-22}$

Debrisoquine oxidation status has been assessed in patients developing peripheral neuropathy on perhexiline therapy. ${ }^{23}$ of this group, $50 \%$ had impaired oxidation status compared with the $9 \%$ expected from population studies, while an unexpectedly low incidence of poor oxidation status was observed in those not developing neuropathy. This demonstrates a clear association between impaired debrisoquine oxidation and propensity to develop perhexiline neuropathy. Poor oxidation secondary to perhexiline hepatitis (producing a phenocopy) is a possible explanation, ${ }^{23}$ an alternative being that perhexiline metabolism is polymorphic and controlled by the same alleles as debrisoquine oxidation.

This article reports a study of perhexiline metabolism in healthy random subjects and was carried out in order to evaluate the second hypothesis.

\section{Patients and methods}

Fifty white British volunteer subjects ( 28 male and 22 female) were randomly selected for investigation, none of whom had been previously phenotyped with debrisoquine or sparteine. A previous history of jaundice, hepatitis, alcohol excess, or perhexiline ingestion caused exclusion from the study, as did any current drug treatments including contraceptive steroids. Liver function was not formally assessed, but assumed to be normal in this healthy population. Individual details are documented in table 1. Three known extensive and three known poor oxidisers of debrisoquine and sparteine, identified from previous investigations, ${ }^{22}$ were also studied for comparison with the random population of nonphenotyped volunteers. Urinary metabolic ratios (UMR) from these known extensive and poor oxidisers are shown in table 2.

TABLE 2 Urinary metabolic ratios from three extensive and three poor oxidisers.

\begin{tabular}{lll}
\hline Patient & Debrisoquine UMR & Sparteine UMR \\
\hline Extensive oxidisers & & \\
JC & 0.2 & 0.78 \\
MH & 0.4 & 0.82 \\
JR & 0.7 & 0.65 \\
Poor oxidisers & & \\
JN & 19.4 & 341 \\
IF & 19.1 & 216 \\
IM & 9.4 & 236 \\
\hline
\end{tabular}

After an overnight fast, a single oral dose of $300 \mathrm{mg}$ perhexiline maleate (Merrell) was swallowed with $150 \mathrm{ml}$ of water. A normal diet was allowed from 3 hours after drug ingestion. Urine produced between 12 and 24 hours after dosage was collected, its volume measured, and an aliquot stored. A plasma sample was collected in a heparinised tube at 24 hours after dosage. Samples were stored at $-20^{\circ} \mathrm{C}$ until analysed.

All samples were analysed for perhexiline, 4monohydroxyperhexiline (MI metabolite), and 4'monohydroxyperhexiline (MIII metabolite). The dihydroxyperhexilines could not be measured since no standards were available.

The details for the preparation of the samples for gas chromatographic analysis are shown in appendix 1 and the details of the gas liquid chromatograph (GLC) in appendix 2. The limits of detection were comparable to other methods currently available. ${ }^{24}$ All results were verified by integrated gas chromatography/mass spectrometry using both VG70/70F (Vacuum Gases) and AEI MS12 (Kratos) equipment.

Previous debrisoquine population studies ${ }^{16}{ }^{17}$ have described oxidation capacity using the urinary metabolic ratio calculated as follows:

$$
\frac{\begin{array}{c}
\% \text { dose excreted as unchanged } \\
\text { debrisoquine }
\end{array}}{\text { \% dose excreted as }} \text { in } 0 \text { to } 8 \text { hour urine. }
$$

Low values $(<1)$ represent extensive oxidisers while high values $(>12 \cdot 5)$ represent grossly impaired oxidisers. The urinary excretion of unchanged perhexiline after a single oral dosage is so small that calculation of a urinary metabolic ratio is not feasible. Urinary excretion rates for MI and MIII metabolites were expressed as $\mu \mathrm{g}$ excreted during the 12 to 24 hour urine collection period.

Plasma concentrations and urinary excretion data were used to compare oxidation ability in the $\mathbf{5 0}$ volunteers and the six subjects of known oxidation status.

\section{Results}

In the following data the mean value \pm SD is given in each instance. The population who had not been previously phenotyped consisted of healthy medical students and nursing and laboratory staff. Twentyeight males were studied aged $22 \pm 5.4$ years with a height of $1.79 \pm 0.05 \mathrm{~m}$ and a weight of $71.8 \pm 9.4$ $\mathrm{kg}$. Twenty-two females were studied aged $26 \cdot 8 \pm 9 \cdot 7$ years with a height of $1.66 \pm 0.06 \mathrm{~m}$ and a weight of $58 \cdot 6 \pm 6 \cdot 7 \mathrm{~kg}$.

The perhexiline results and the MI metabolite 
results in the $\log _{10}$ form exhibit a marked bimodal distribution.

A 24-hour plasma MI metabolite concentration of $0.56 \pm 0.18 \mu \mathrm{g} / \mathrm{ml}$ was observed in 47 subjects, while three subjects (test numbers 4, 26, and 48) had much lower concentrations of $0.02 \pm 0.005 \mu \mathrm{g} / \mathrm{ml}$ $(t=5 \cdot 15$, df 48, p $<0 \cdot 001)$.

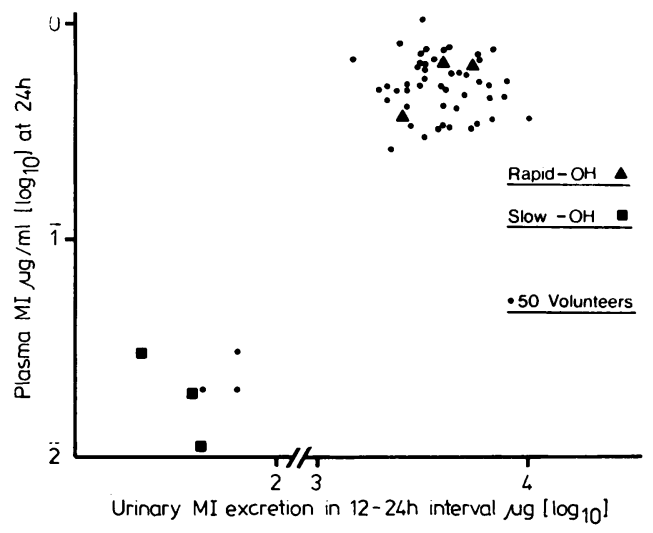

FIG 1 The 24-hour plasma concentration of perhexiline MI metabolite concentration and the 12 to 24-hour urinary MI metabolite excretion in 50 random white British subjects of unknown phenotype. Also shown are the results in known extensive ( $\Delta$ ) and poor ( $\mathbf{\square})$ metabolisers of debrisoquine and sparteine.

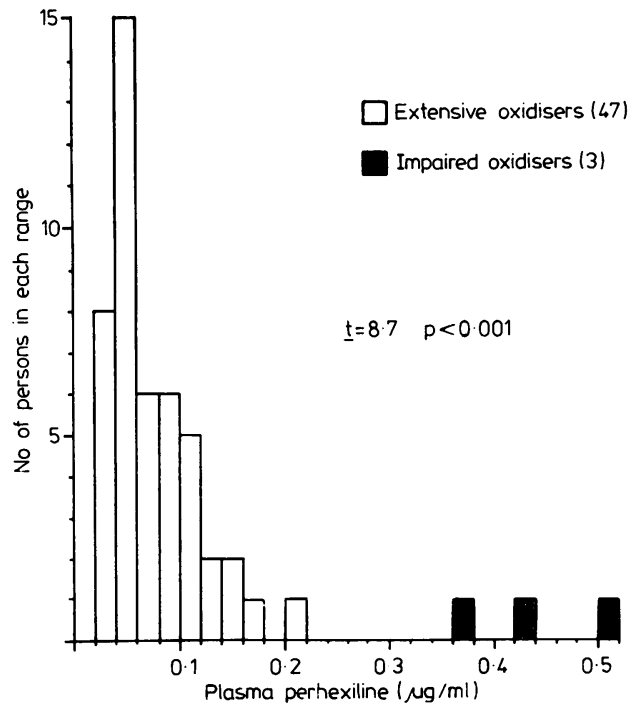

FIG 2 Plasma 24-hour perhexiline concentrations in 50 random white British subjects.

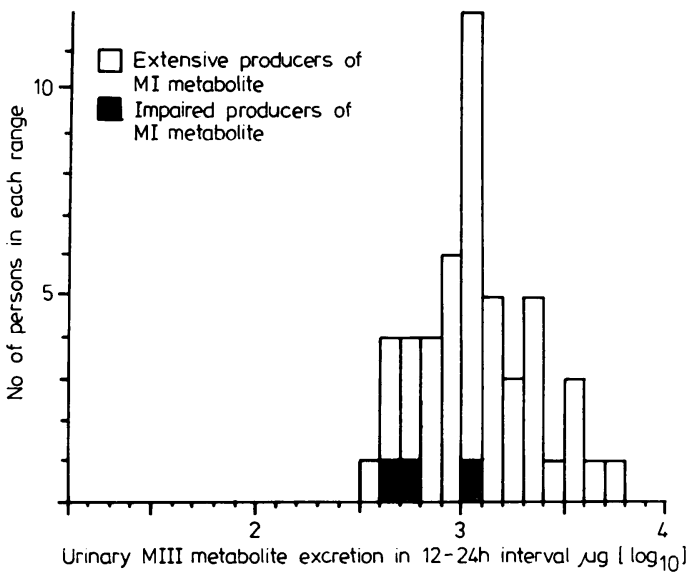

FIG 3 Urinary excretion of the MIII metabolite of perhexiline in 50 random white British subjects.

The urinary excretion of the MI metabolite in the time interval 12 to 24 hours was $4205 \pm 1791 \mu \mathrm{g}$ in 47 subjects, while the three anomalous subjects excreted $46 \pm 29 \mu \mathrm{g}(t=3.99$, df $48, \mathrm{p}<0.001)$.

These two measurements, that is, plasma $M$ metabolite concentration and urinary MI metabolis excretion, clearly distinguish two sub-groups perhexiline metabolisers with three persons (test numbers 4,26 , and 48 ) having a profound relative inability to produce the MI metabolite (fig 1).

The 24-hour plasma perhexiline concentration was $0.072 \pm 0.04 \mu \mathrm{g} / \mathrm{ml}$ in the 47 extensive oxidisers while the three poor oxidisers gave a value of $0.43 \pm 0.065 \mu \mathrm{g} / \mathrm{ml}$ (fig $2 ; t=8.7, \mathrm{df} 48, \mathrm{p}<0.001$ ).

The three previously phenotyped poor oxidisers of debrisoquine and sparteine were also found to be poor oxidisers of perhexiline, while the three known extensive oxidisers of debrisoquine and sparteine were also found to be extensive oxidisers of perhexiline (table 1, fig 1).

Plasma MIII metabolite was virtually undetectable. Urinary excretion of MIII was $1515 \pm 1003 \mu \mathrm{g}$ in the 12 to 24 hour period in extensive metabolisers and $671 \pm 288 \mu \mathrm{g}$ in the three poor producers of the MI metabolite, thus demonstrating no significant $\mathrm{N}$ difference between the phenotypes with regard to $N$ MIII production. There is no bimodal distribution of MIII metabolite excretion (fig 3).

When the urinary excretion of metabolites in the 12 to 24 hour period is expressed as a percentage of $\stackrel{\varrho}{ᄃ}$ the perhexiline dose ingested, the following figures $\stackrel{Ð}{+}$ are obtained. The 47 extensive metabolisers excreted $1.40 \pm 0.6 \%$ of the dose as the MI metabolite compared with $0.014 \pm 0.008 \%$ in the three poor 
metabolisers $(t=3.99$, df $48, \mathrm{p}<0.001)$. The 47 extensive producers of MI metabolite excreted $0.47 \div 0.37 \%$ of the dose as MIII metabolite compared with $0 \cdot 22 \pm 0.09 \%$ in the poor MI metabolite producers. There is no significant difference between the phenotypes with regard to MIII excretion.

\section{Discussion}

Patients with advanced chronic hepatic disease metabolise many drugs remarkably normally, ${ }^{25}$ but prolonged half lives of phenylbutazone ${ }^{26}$ and meprobamate $^{27}$ have been demonstrated in some patients with liver disorder indicating that drug metabolism can be affected. An impaired hepatic oxidation of debrisoquine has been found in $50 \%$ of patients developing peripheral neuropathy on perhexiline therapy, ${ }^{23}$ but hepatic dysfunction due to perhexiline could not be completely excluded as the cause for the observed impaired debrisoquine oxidation. However, patients developing perhexiline neuropathy with impaired debrisoquine oxidation did have normal biochemical liver function tests. Since 8 to $9 \%$ of British whites are poor oxidisers of debrisoquine, ${ }^{1617}$ it was thought likely that poor oxidisers of debrisoquine were also poor oxidisers of perhexiline, with accumulation of the unchanged drug causing neuropathy. ${ }^{23}$ Two questions arise from these findings. Is there a genetic polymorphism for perhexiline hydroxylation? If so, is the genetic control the same as in the debrisoquine polymorphism?

The use of perhexiline maleate for population oxidation phenotyping has given direct rather than inferred information about perhexiline hydroxylation. By testing healthy subjects on no current drug treatments, the element of doubt about hepatic dysfunction due to perhexiline or other drugs is excluded. Conclusive evidence for polymorphism has been provided by the bimodal distribution of plasma perhexiline concentration, plasma MI metabolite concentration, and urinary MI metabolite excretion (fig 1). Known poor oxidisers of debrisoquine and sparteine are also poor oxidisers of perhexiline, and known extensive oxidisers of debrisoquine and sparteine are also extensive oxidisers of perhexiline (table 1, fig 1). The genetic control of perhexiline hydroxylation polymorphism is, therefore, identical in white British subjects to that for debrisoquine and other compounds (for example, sparteine).

Population ${ }^{16}{ }^{17}$ and family ${ }^{17}$ studies have indicated that the oxidation of debrisoquine is regulated genetically by two alleles referred to as the $\mathrm{D}^{\mathrm{H}}$ (extensive oxidation) and $\mathrm{D}^{\mathrm{L}}$ (impaired oxidation) alleles. $^{28}$ Subjects homozygous for the recessive allele $\left(D^{L} D^{L}\right)$ have grossly impaired hepatic oxidation with metabolic ratios $>12.5$ and represent 8 to $9 \%$ of the British white population. Both the homozygote $\mathrm{D}^{\mathrm{H}} \mathrm{D}^{\mathrm{H}}$ and the heterozygote $\mathrm{D}^{\mathrm{H}} \mathrm{D}^{\mathrm{L}}$ are extensive oxidisers. ${ }^{17}$ The majority of British whites are unequivocally extensive oxidisers with metabolic ratios $<1$. Several subjects in population studies have intermediate metabolic ratios $>1$, but $<12 \cdot 5$, and so their phenotypes are doubtful (and could only be ascertained with certainty by pedigree analysis).

A remarkably clear bimodal distribution of $\mathrm{MI}$ metabolite results is apparent from perhexiline phenotyping with no 'intermediates' in healthy subjects. The perhexiline phenotyping test seems, therefore, superior to other oxidation phenotyping tests and so is probably suitable to assess patients before anti-anginal therapy with the drug.

An interesting and previously unrecorded side effect of perhexiline was uncovered during this population study. Of 22 females investigated, two were menstruating at the time and one was postmenopausal. Of the 19 females remaining, five $(26 \%)$ started an abnormal menstruation within 18 hours of ingesting perhexiline. This phenomenon was not related to any one part of the menstrual cycle and blood loss appeared to follow painful uterine contraction. The mechanism for this phenomenon is unknown, but a local effect on endometrial prostaglandin balance may be responsible. The synthetic prostaglandin $\mathrm{PGE}_{2}$-analogue, Sulprostron, is known to induce menstruation in $92 \%$ of females after intramuscular dosage. ${ }^{29}$ If the perhexiline phenotyping test is to be carried out in females of childbearing age, it should be performed during menstruation to minimise this distressing side effect.

The pharmacokinetic fate of perhexiline in the human body is unclear. After oral dosage perhexiline is well absorbed, the majority of excretion being via the urine, but some faecal excretion occurs. ${ }^{14} \mathrm{~A}$ urinary excretion half life of perhexiline or its metabolites ranging from 3 to 22 days has been demonstrated $^{14}$ implying large inter-individual variations of metabolism. In the extensive oxidisers identified from this phenotyping test, a surprisingly small percentage of the ingested perhexiline was excreted in the urine as its major metabolites: $1.40 \pm 0.008 \%$ as MI metabolite and $0.47 \pm 0.37 \%$ as MIII metabolite. Poor oxidisers excreted $0.014 \pm$ $0.008 \%$ as MI metabolite and $0.22 \pm 0.09 \%$ as MIII metabolite. On repeated doses, accumulation would be obviously very much more likely to occur in poor metabolisers than in extensive metabolisers. 
Perhexiline is extremely lipid soluble and binding to fat stores throughout the body with subsequent slow release might explain the prolonged half life and slow excretion observed.

Animal studies demonstrate a majority of perhexiline or metabolites to be present in hepatic and pulmonary tissue ${ }^{30}$ both rich in cytochrome P-450 but not normally rich in fat. A persistence of radioactivity in rat bile after oral ${ }^{14} \mathrm{C}$ radio-labelled perhexiline indicates biliary excretion. ${ }^{30}$ The complicated pharmacokinetics of perhexiline remain poorly understood.

A genetic relative inability to oxidise debrisoquine, sparteine, and now perhexiline has been demonstrated. This inherited 'defect' may not apply to all drug oxidations. ${ }^{31}$ Perhexiline phenotyping has shown that both extensive and severely impaired producers of 4-monohydroxyperhexiline (MI metabolite) can produce and excrete similar amounts of $4^{\prime}$-monohydroxyperhexiline (MIII metabolite), thus demonstrating a stereotactic substrate preference for oxidation by a hepatic cytochrome P-450.

Perhexiline phenotyping distinguishes subjects with impaired oxidation governed by the debrisoquine type $\mathbf{D}^{\mathbf{H}} \mathbf{D}^{\mathbf{L}}$ allele genetic system more clearly than debrisoquine or other tests. It defines clearly those at risk from accumulation of perhexiline, debrisoquine, and therefore other drugs controlled by the same alleles. Consequently, it may well be a useful tool for excluding those at risk from the dangerous toxic side effects of these compounds.

\section{References}

1 Afzal M, Kafetzakis EM. Assessment of perhexiline maleate in angiographically proven intractable angina: a double-blind trial. Am Heart J 1978;96:350-4.

2 Burns-Cox CJ, Chandrasekhar KP, Ikram H, et al. Clinical evaluation of perhexiline maleate in patients with angina pectoris. Br Med J 1971;4:546-8.

3 Nick J, Dudognon P, Escourolle R, et al. Neurological disorders and perhexiline maleate therapy. Clinical study of 10 cases. Neuropathological, pharmacokinetic and biochemical studies. Rev Neurol 1978;134:103-14.

4 Bousser MG, Bouche P, Hauw JJ, et al. Neuropathies périphériques au maléate de perhexiline. Ann Cardiol Angeiol (Paris) 1977;26:493-9.

5 Lewis D, Wainwright HC, Kew MC, et al. Liver damage associated with perhexiline maleate. Gut 1979;20:186-9.

- Forbes GB, Rake MO, Taylor DJ. Liver damage due to perhexiline. J Clin Pathol 1980:32:1282-5.

7 Pilcher J, Chandrasekhır KP, Russell RJ, et al. Longterm assessment of perhexiline maleate in angina pectoris. Postgrad Med J 1973;49(suppl 3):115-8.

8 Houdent CE, Wolf LM, Corriat A. Liver during perhexiline hypoglycaemia. Lancet 1977 ;ii:1028.

9 Tomlinson IW, Rosenthal FD. Proximal myopathy after perhexiline maleate treatment. Br Med J 1977;i:1319-20.

10 Hutchinson WM, Williams J, Cawler J. Papilloedema in patients taking perhexiline maleate. $\mathrm{Br}$ Med J 1978 ; i:305.
11 Pessayre D, Bichara M, Feldmann G, et al. Perhexiline maleate-induced cirrhosis. Gastroenterology 1979;76: 170-7.

12 Crinquette JF. Perhexiline-induced cirrhosis. Acta Gastroenterol Belg 1982;44:391-5.

13 Singlas E, Simon $P$. The contribution of pharmacokinetics in explaining a drug's side-effects: the case of perhexiline. Therapie $1981 ; 36: 285-8$.

14 Wright GJ, Leeson GA, Zeiger AV, Lang JF. The $\frac{C}{\sigma}$ absorption, excretion and metabolism of perhexiline $\overline{\bar{\omega}}$ maleate by the human. Postgrad Med J 1973;49(suppl 3): 8-15.

15 Singlas E, Goujet MA, Simon P. Pharmacokinetics of perhexiline maleate in anginal patients with and without os peripheral neuropathy. Eur J Clin Pharmacol 1978;14: $\vec{\circ}$ 195-201.

16 Mahgoub A, Idle JR, Dring LG, Lancaster R, Smith RL. $\vec{\omega}$ Polymorphic hydroxylation of debrisoquine in man. o Lancet 1977 ;ii:584-6.

17 Evans DAP, Mahgoub A, Sloan TP, Idle JR, Smith RL. A family and population study of the genetic poly- is morphism of debrisoquine oxidation in a white British $\rightarrow$ population. J Med Genet 1980;17:102-5.

18 Idle JR, Mahgoub A, Lancaster R, Smith RL. Hypo- N tensive response to debrisoquine and hydroxylation $\mathrm{O}$ phenotype. Life Sci 1978;22:979-84.

19 Sloan TP, Idle JR, Smith RL. Influence of DH/DL alleles regulating debrisoquine oxidation on phenytoin hydro- $\mathbb{D}$ xylation. Clin Pharmacol Ther $1981 ; 29: 493-7$.

20 Shah RR, Oates NS, Idle JR, Smith RL. Genetic impairment of phenformin metabolism. Lancet 1980;i:1147.

21 Dayer P, Balant L, Courvoisier F, et al. The genetic $\vec{c}$ control of bufuralol metabolism in man. Eur J Drug Metab Pharmacol 1982;7:73-7.

22 Evans DAP, Harmer D, Downham DY, et al. The genetio control of sparteine and debrisoquine metabolism in mat with new methods of analysing bimodal distributionf J Med Genet 1983;20:321-9.

${ }^{23}$ Shah RR, Oates NS, Idle JR, Smith RL, Lockhart JD. Impaired oxidation of debrisoquine in patients with perhexiline neuropathy. Br Med J 1982;284:295-9.

24 Amoah AG, Gould BJ, Parke DV. Single dose perhexiline pharmacokinetics in human volunteers. $B r \quad J$ Clin Pharmacol 1982;14:623.

25 Anonymous. Drug metabolism in disease. Lancet 1974 ; : 790-1.

26 Levi AJ, Sherlock S, Walker D. Phenylbutazone and isoniazid metabolism in patients with liver disease in relation to previous drug therapy. Lancet $1968 ; \mathbf{i}: 1275-9$.

${ }^{27}$ Held $\mathrm{H}$, von Oldershausen HF. Zur pharmakokinetik von meprobamat bei chronischen hepatopathien und arzneimittelsucht. Klin Wochenschr 1969;47:78-80.

28 Sloan TP, Mahgoub A, Lancaster R, Idle JR, Smith RL. Polymorphism of carbon oxidation of drugs and clinical implications. Br Med J 1978 ;ii:655-7.

29 Csapo AI, Peskin EG, Pulkkinen M, et al. 'Menstrual I induction' with Sulprostron. Prostaglandins 1982;24: 윽 657-62.

30 Leeson GA, Zeiger AV, Lang JF, Wright GJ. Metabolic N fate of perhexiline- ${ }^{14} \mathrm{C}$ maleate. Fed Proc 1969;28:798.

31 Küpfer A, Dick B, Preisig R. A new drug hydroxylation $\mathbb{O}$ polymorphism in man: incidence of mephenytoin hydrox- N xylation deficiency phenotypes in a Swiss population. $\omega$ Program and Abstracts 8th European Workshop in Drug Metabolism, Leige, Belgium, 1982, Abstract 284:160.

Correspondence and requests for reprints to $\stackrel{\mathscr{D}}{\rightarrow}$ Dr R G Cooper, Nuffield Unit of Pharmacogenetics, 
Department of Medicine, University of Liverpool, Liverpool L69 3BX.

\section{APPENDIX 1 Details of analytical procedure.}

\section{PLASMA}

(1) $2 \mathrm{ml}$ plasma and $1 \mathrm{ml}$ IM Tris buffer $\mathrm{pH} 10 \cdot 5+10 \mu \mathrm{l}$ nortriptyline, $200 \mu \mathrm{g}$ per $\mathrm{ml}$ water $+20 \mathrm{ml}$ Analar diethyl ether.

(2) Shake for 5 minutes.

(3) Transfer ether to clean tube. Evaporate to dryness at $45^{\circ} \mathrm{C}$.

(4) Add $0.75 \mathrm{ml}$ ether and transfer to a small flat-bottomed tube. Dry at $45^{\circ} \mathrm{C}$.

(5) Add $12.5 \mu$ l heptafluorobutyric anhydride reagent (Sigma) + $0.5 \mathrm{ml} 0.05 \mathrm{M}$ triethylamine in toluene.

(6) Stopper and heat at $75^{\circ} \mathrm{C}$ for 20 minutes.

(7) Cool for 5 minutes.

(8) Add $0.75 \mathrm{ml}$ distilled water.

(9) Shake for 5 minutes.

(10) Add $1 \mathrm{ml} 5 \% 880$ ammonia in water.
(11) Shake for 5 minutes.

(12) Centrifuge $1000 \mathrm{~g}$ for 5 minutes.

(13) Transfer upper toluene layer to clean storage vial with plastic stopper.

(14) Store at $-20^{\circ} \mathrm{C}$

(15) Inject $2 \mu l$ into GLC.

URINE

Same as for plasma except the nortriptyline volume in step 1 is changed to $100 \mu \mathrm{l}$.

Inject $0.4 \mu \mathrm{l}$ in step 15 since the amount of $\mathrm{Ml}$ is usually much larger.

APPENDIX 2 Details of gas/liquid chromatography.

Sigma (Mk II)

OV 7 on Gas Chrom Q 100/120 mesh (Phasep)

Nitrogen Gas $40 \mathrm{ml} / \mathrm{min}$ column

" " $60 \mathrm{ml} / \mathrm{min}$ through detector

$7 \mathrm{ft}$ column (glass) $2 \mathrm{~mm} 1 \mathrm{D}$

Injection $250^{\circ} \mathrm{C}$ Column $215^{\circ} \mathrm{C}$ Detector $300^{\circ} \mathrm{C}$

${ }^{63} \mathrm{M}$-Electron Capture Detector 